\title{
Percepção do enfermeiro sobre os efeitos do trabalho noturno em sua vida
}

Recebido em: 09/01/2011

Aceito em: 26/07/2011
Juliana Balbinot Reis Girondi ${ }^{1}$

Francine Lima Gelbcke ${ }^{2}$

Este trabalho objetivou identificar as percepções dos enfermeiros de um hospital universitário do sul do país acerca dos efeitos do trabalho noturno sobre a saúde e vida social. Trata-se de uma pesquisa qualitativa utilizando questionários e análise temática de Bardin. Participaram do estudo 16 enfermeiros. Conclui-se que o trabalho afeta diretamente o equilíbrio psíquico do trabalhador, uma vez que não há como dissociar a saúde psicológica da física, e por isso o trabalho noturno demanda uma reformulação geral de hábitos de vida.

Descritores: Trabalho Noturno, Esgotamento Profissional, Saúde Ocupacional.

\section{Perception of the nurses on the effects of night work in their lives}

This study aimed to identify the perceptions of nurses at a university hospital in southern Brazil, about the effects of night work on their health and social lives. This is a qualitative research using questionnaires and thematic analysis of Bardin. The study included sixteen nurses. It was concluded that work directly affects the mental balance of the employee, since we cannot separate the psychological health from physical health, and that is why night work demands a general reorganization of lifestyle.

Descriptors: Night Work, Burnout, Occupational Health.

\section{Percepción de los enfermeros sobre los efectos del trabajo nocturno en sus vidas}

Este estudio tuvo como objetivo identificar las percepciones de los enfermeros en un hospital universitario en el sur de Brasil, sobre los efectos del trabajo nocturno en la salud y la vida social. Se trata de una investigación cualitativa mediante cuestionarios y el análisis temático de Bardin. El estudio incluyó dieciséis enfermeros. Se concluyó que el trabajo afecta directamente el equilibrio mental del trabajador, ya que no podemos separar la salud psicológica de la física de la salud, y por qué el trabajo nocturno requiere una revisión general del estilo de vida.

Descriptores: Trabajo Nocturno, Burnout, Salud Ocupacional.

\section{INTRODUÇÃO}

$\mathrm{N}$ a sociedade moderna, pode-se perceber a intensidade das exigências do trabalho e as ameaças à vida que daí podem surgir. Nessa perspectiva, o trabalho como categoria social está sujeito a múltiplos condicionantes. As condições de trabalho e suas patologias estão estreitamente relacionadas a diferentes variáveis, como a organização do trabalho, e refletem valores e regras da sociedade ${ }^{(1)}$. Logo, o desgaste do trabalhador é condicionado por condições gerais de vida e pelas relações específicas desse trabalho ${ }^{(2)}$.

Trabalhar é um ato imprescindível para as pessoas, pois se refere à própria sobrevivência e ao condicionamento social do indivíduo ${ }^{(3)}$. Dessa forma, a atividade profissional não é só um modo de ganhar a vida, mas também uma forma de inserção social em que aspectos psíquicos e físicos estão fortemente implicados. No entanto, o trabalho pode ser um fator de deterioração, envelhecimento e doenças graves.
A relação entre o trabalho e a vida dos trabalhadores tem sido objeto de vários estudos para que se possa compreender como as diversas formas de organização de trabalho agem sobre o pensar e o sentir dos trabalhadores ${ }^{(4)}$.

No Brasil, de modo geral, a relação saúde-trabalho é problemática, devido especialmente à deficiência de condições de vida e trabalho adequadas. Direcionando essa realidade para o contexto de enfermagem, constatase, através da literatura, que esses profissionais possuem condições de trabalho insatisfatórias, desencadeadas por problemas multifatoriais, que vão desde a baixa remuneração até esquemas de horários de trabalho adotados ${ }^{(5-8)}$.

Em meio a esse processo expansivo, percebe-se que o trabalho em turnos existe há tempos. Entre os mais antigos grupos profissionais que trabalham em sistemas de turnos se encontram os dos serviços de saúde, aos quais os enfermeiros e demais membros da equipe (técnicos

1 Doutoranda em Enfermagem pela Universidade Federal de Santa Catarina (UFSC). Especialista em Enfermagem Oncológica. Especialista em Administração Hospitalar Pública pela Universidade Federal de Santa Catarina-UFSC. Enfermeira Assistencial da Unidade de Clínica Médica I, do Hospital Universitário - HU, Florianópoli. Enfermeira Assessora de Vigilância Epidemiológica em Saúde da Regional Continente, Florianópolis. Membro do Grupo de Pesquisa GESPI/UFSC. E-mail: julibreis@hotmail.com

2 Doutora em Enfermagem pela Universidade Federal de Santa Catarina (UFSC). Mestre em Enfermagem pela Escola de Enfermagem Alfredo Pinto (UNI-RIO). Diretora de Enfermagem do Hospital Universitário Professor Polydoro Ernani de São Thiago. 
e auxiliares) que compõem a categoria profissional de enfermagem estão submetidos ${ }^{(9)}$. $O$ trabalho em turnos é objeto de investigações que tem como perspectiva avaliar seus inconvenientes nos diferentes âmbitos da vida dos indivíduos, principalmente os que trabalham no período noturno, já que se encontram em dessincronizaçäo com o próprio ritmo biológico e em desarmonia com o ambiente social no qual estão inseridos (10-17).

Este estudo objetivou identificar as percepções dos enfermeiros acerca dos efeitos do trabalho noturno sobre sua saúde e vida social.

\section{METODOLOGIA}

Este estudo foi realizado no Hospital Universitário Professor Ernani Polydoro de São Thiago, da Universidade Federal de Santa Catarina (HU/UFSC).

Os sujeitos participantes deste estudo foram: enfermeiros não ocupantes de cargo de chefia, que desempenham seu trabalho há mais de um ano no período noturno e que concordaram em participar do estudo.

A coleta de dados ocorreu através de questionário, abordando aspectos gerais do trabalho noturno: vantagens, desvantagens e seus efeitos no cotidiano, principalmente na organização das atividades da vida diária. O questionário abordou ainda as percepções sobre a saúde e vida social, assim como suas mudanças a partir do trabalho noturno.

O levantamento de dados ocorreu em janeiro de 2007, após aprovação da instituição em estudo e do Comitê de Ética em Pesquisa. Os dados foram analisados de acordo com as etapas propostas por Bardin ${ }^{(18)}$.

\section{RESULTADOS E DISCUSSÃO}

Foi distribuído um total de 48 questionários, por existir no $\mathrm{HU}$ 13 serviços que trabalham em sistema de plantão; responderam ao questionário 16 enfermeiros. As unidades de significados originaram as categorias apresentadas a seguir.

\section{Caracterização da força de trabalho e o desgaste psicossocioemocional}

Com base nas variáveis independentes relacionadas a estado civil, faixa etária, gênero, tempo de serviço na profissão e no plantão noturno, titulação, local/setor de trabalho e jornada de trabalho, caracterizou-se a força de trabalho. Também foram identificadas as queixas psicossocioemocionais relacionadas ao trabalho noturno.

O maior número de enfermeiros estava entre a faixa etária de 40 a 50 anos (56,25\%). A proporção de trabalhadores com queixas relacionadas ao trabalho noturno é estatisticamente a mesma, independentemente da faixa etária.

Com relação ao gênero, $93,75 \%$ são do sexo feminino, enquanto $6,25 \%$ são do sexo masculino. A proporção de mulheres com queixas relacionadas ao trabalho noturno pode ser considerada estatisticamente maior do que a proporção de homens. A enfermagem é exercida majoritariamente por mulheres, sendo comum a sobrecarga de trabalho dessas,
Tabela 1 - Distribuição percentual das variáveis do estudo

\begin{tabular}{|c|c|c|}
\hline VARIAVÉIS & $\mathbf{N}$ & $\%$ \\
\hline \multicolumn{3}{|l|}{ Faixa etária } \\
\hline $20 \mid-30$ anos & 03 & 18,75 \\
\hline $30 \mid-40$ anos & 02 & 12,5 \\
\hline $40 \mid-50$ anos & 09 & 56,25 \\
\hline 50 ou mais & 02 & 12,5 \\
\hline \multicolumn{3}{|l|}{ Gênero } \\
\hline Masculino & 01 & 6,25 \\
\hline Feminino & 15 & 93,75 \\
\hline \multicolumn{3}{|l|}{ Tempo de serviço na profissão } \\
\hline$<01$ ano & - & - \\
\hline $01 \mid-05$ anos & 02 & 12,5 \\
\hline $05 \mid-10$ anos & 02 & 12,5 \\
\hline $10 \mid-15$ anos & 04 & 25 \\
\hline $15 \mid-20$ anos & 02 & 12,5 \\
\hline 20 ou mais & 06 & 37,5 \\
\hline \multicolumn{3}{|c|}{ Tempo de serviço no plantão noturno } \\
\hline $01 \mid-5$ anos & 02 & 12,5 \\
\hline $05 \mid-10$ anos & 03 & 18,75 \\
\hline $10 \mid-15$ anos & 05 & 31,25 \\
\hline $15 \mid-20$ anos & 03 & 18,75 \\
\hline 20 ou mais & 03 & 18,75 \\
\hline \multicolumn{3}{|l|}{ Jornada de trabalho } \\
\hline Única & 03 & 18,75 \\
\hline Dupla & 13 & 81,25 \\
\hline \multicolumn{3}{|l|}{ Setor de trabalho } \\
\hline Emergência adulta & 03 & 18,75 \\
\hline Clínica médica & 05 & 31,25 \\
\hline Clínica cirúrgica & 02 & 12,5 \\
\hline Neonatologia & 03 & 18,75 \\
\hline Alojamento conjunto & 01 & 6,25 \\
\hline Ginecologia & 02 & 12,5 \\
\hline \multicolumn{3}{|l|}{ Titulação } \\
\hline Generalista & 07 & 43,75 \\
\hline Mestre & 04 & 25 \\
\hline Especialista & 05 & 31,25 \\
\hline
\end{tabular}

devido às atividades domésticas e a dupla jornada, que pode repercutir em agravos à saúde ${ }^{(19)}$.

Quanto ao tempo de serviço na profissão, 37,5\% dos trabalhadores possuem mais de 20 anos de atuação. Avaliando o tempo de serviço em plantão noturno, a maior parte esteve entre dez e 14 anos de trabalho noturno (31,25\%). Logo, a proporção de queixas relacionadas ao trabalho noturno é considerada estatisticamente maior nos profissionais que trabalharam por dez anos ou mais. No que refere à faixa etária, o tempo de serviço em plantão noturno e o fato de ter outras 
atividades durante o dia (dupla jornada) são fatores agravantes para o desgaste do trabalhador enfermeiro ${ }^{(20)}$.

Em relação à jornada de trabalho, 18,75\% possuem jornada única, enquanto $81,25 \%$ têm dupla jornada. A proporção de queixas relacionadas ao trabalho noturno é considerada estatisticamente maior entre os profissionais que possuem jornada dupla de trabalho.

\section{O processo de trabalho do enfermeiro no turno noturno}

Ao serem interrogados sobre como refletem sobre a organização do trabalho noturno, o que diferencia o trabalho noturno do diurno, vantagens, facilidades e dificuldades de desenvolver suas atividades, os enfermeiros fizeram várias colocações. A partir dessas respostas, obtiveram-se os significados, que foram agrupados nas seguintes subcategorias:

\section{- Abordagem administrativa}

Os significados dessa subcategoria compreendem a metodologia do processo de enfermagem, que é realizada com melhor qualidade no período noturno devido ao fato de o enfermeiro ter maior acesso aos prontuários e exames, o que permite uma visão mais holística do paciente. As atividades para os enfermeiros no período noturno estão centradas em atividades técnicas mais complexas, coordenação e supervisão da assistência de enfermagem, controle e apoio da equipe de enfermagem, bem como procedimentos privativos do enfermeiro. Os aspectos negativos envolvem a situação de que os funcionários do noturno são mais "isolados" do dia, principalmente nas relações com outros setores que não trabalham em esquema de plantão; a questão de dificuldades de trabalho com alguns plantonistas médicos, o que interfere diretamente na qualidade da assistência prestada e a dificuldade de coberturas de plantão para o período noturno.

\section{- Abordagem assistencial}

Os significados dessa subcategoria destacam que o enfermeiro não fica envolvido apenas com as questões burocráticas da unidade, participando mais ativamente da assistência. Também, durante o período noturno, o fluxo de pessoas no hospital é menor, o que confere um ambiente mais tranquilo, com menos estresse e maior possibilidade de disponibilidade de tempo para ofertar ao paciente e seus familiares. Ao trabalhar no noturno, há a questão de flexibilidade de horários, o que permite um duplo vínculo empregatício. Os enfermeiros também consideram o trabalho noturno mais produtivo do que o diurno.

\section{- Abordagem educacional}

Como a noite é o período de sono e repouso para o ser humano, as atividades de educação em saúde desenvolvidas pelo enfermeiro ficam restritas. Da mesma forma, a maioria dos cursos e treinamentos relacionados ao processo de educação permanente é realizada no turno diurno. Como a maioria dos enfermeiros possui outro vínculo empregatício, fica também prejudicada nessa situação.

\section{Os significados do trabalho noturno na vida dos enfermeiros} Ao serem questionados se consideram sua jornada de trabalho estressante, metade dos enfermeiros respondeu que não e metade respondeu que sim, justificando essa resposta pelo fato de terem outro emprego no período diurno.

Quanto ao grau de satisfação em trabalhar no período noturno, $75 \%$ dos enfermeiros (12 respondentes) relataram satisfação pela possibilidade de ter outra renda e estar mais próximo do paciente ao desenvolver a assistência; $25 \%$ (quatro respondentes) afirmaram que estão insatisfeitos por saber que, ao longo do tempo, o trabalho noturno é prejudicial à saúde.

Onze enfermeiros $(68,75 \%)$ afirmaram que suas famílias estão satisfeitas com seu horário de trabalho, enquanto um $(6,25 \%)$ relatou que sua família está insatisfeita e quatro (25\%) que a família não tem opinião sobre esse fato.

Ao serem questionados sobre o ritmo de trabalho, quando instigados a refletirem sobre seu estado geral após um plantão noturno, cinco enfermeiros relataram sentir-se bem, cinco regular, dois estressados, um esgotado e três sem estímulo. Quando questionados sobre a percepção de, nos últimos meses, estarem trabalhando além do limite, $68,75 \%$ afirmaram que às vezes, $18,75 \%$ que quase sempre e $12,5 \%$ além do limite. Essas situações acarretam alterações físicas, tais como quadros de ansiedade, aumento da pressão arterial, cefaleia, irritabilidade, cansaço, insônia, alteração de hábitos alimentares, assim como alterações psicossocioemocionais, como dificuldades de relacionamento, alterações de humor, prejuízos nas relações familiares e no lazer, dificuldade em estudar. Uma das necessidades humanas básicas mais importantes é o sono, e o não-atendimento a essa necessidade, principalmente após a jornada de trabalho noturno, acarreta condições desfavoráveis ao estado físico e mental do indivíduo. Tais condições incluem sensações de cansaço, depressão, falta de controle e dificuldades em realizar tarefas ${ }^{(20)}$. Apesar dessas situações, 13 enfermeiros (81,25\%) salientaram que as mudanças no ritmo circadiano não interferem na conduta profissional ao atender o paciente, enquanto três $(18,75 \%)$ afirmam que interferem, já que o desenvolvimento de atividades fica mais lento em virtude do cansaço físico e mental ocasionado pela jornada excessiva de trabalho.

\section{As percepções dos enfermeiros em relação ao trabalho noturno}

Ao serem interrogados sobre a percepção em relação ao trabalho noturno, os enfermeiros fizeram várias colocações. A partir dessas respostas, obtiveram-se os significados, que 
foram agrupados nas seguintes subcategorias: aspectos positivos e negativos.

\section{- Aspectos positivos}

O processo de trabalho no turno noturno é funcional e não há a assistência integral, como no período diurno. Dessa forma, recai sobre o enfermeiro a tomada de decisões. Isso lhe confere maior aproximação com a equipe de trabalho, sendo um fator considerado positivo.

Como aspecto favorável, foi ressaltada a situação de a equipe de enfermagem ser fixa, o que confere maior integração entre os profissionais e a efetividade da assistência, diferentemente do diurno, quando existe um maior número de funcionários e a rotatividade é consideravelmente maior. Cabe elucidar que a dinâmica da organização do trabalho da equipe de enfermagem num hospital é realizada obedecendo a escalas mensais de distribuição dos plantões e de distribuições de tarefas nos postos de trabalho. No HU/UFSC, na escala de plantões noturnos, a equipe de enfermagem trabalha em esquemas de 12 horas trabalhadas por 60 horas de folga.

\section{- Aspectos negativos}

Os significados dessa subcategoria compreendem: o trabalho noturno caracteriza-se como solitário e desgastante e que gera sofrimento biológico no longo prazo. Toda a situação de trabalho envolve pelo menos três aspectos: físico, cognitivo e psíquico. Além disso, cada qual pode determinar uma sobrecarga, e essa, consequentemente, levar à doença do trabalhador ${ }^{(14,16,20)}$. No entanto, é preciso entender que cada indivíduo possui formas de amenizar e/ou eliminar essa sobrecarga; logo, a satisfação e o prazer no trabalho são potentes formas de evitar as doenças decorrentes do trabalho laboral.

\section{CONSIDERAÇÕES FINAIS}

As pressões oriundas do trabalho afetam diretamente o equilíbrio psíquico do trabalhador, uma vez que não há como dissociar a saúde psicológica da saúde física. Por isso, podese concluir que, na relação homem-trabalho, conseguimos detectar momentos em que o trabalho conduz ao sofrimento psíquico e momentos em que o trabalho conduz à plena realização profissional e até pessoal.

Cabe, neste momento, propor uma reflexão acerca da análise na prática das situações geradoras de satisfação e insatisfação do enfermeiro trabalhador no período noturno. Essa reflexão baseia-se na premissa de favorecer a conscientização e o conhecimento das necessidades psicossociais dos enfermeiros, além de dispor do diagnóstico da qualidade de vida desse em seu local de trabalho. Porque somente a partir desses conhecimentos é que haverá a oportunidade de intervir nessa realidade, mudando-a para algo melhor.

\section{Referências}

1. Laurell AC. Saúde e trabalho: os enfoques teóricos. In: Nunes Everardo D,

organizador. As ciências sociais em saúde na América Latina: tendência

e perspectivas. Brasília: OPAS; 1985.

2. Picaluga IF. Saúde e trabalho. Petrópolis: Vozes; 1982.

3. Lunardi FWD. Prazer e sofrimento no trabalho: contribuiçōes à organização do processo de trabalho da enfermagem [dissertação]. Porto Alegre: Universidade Federal do Rio Grande do Sul; 1995.

4. Lopes V. O trabalho noturno do profissional de enfermagem: o sofrimento do trabalho na visão da ergonomia. Estudo de caso de uma Unidade de Emergência Hospitalar [dissertação]. Florianópolis: Universidade Federal de Santa Catarina; 2000.

5. Aquino EMLI. Saúde e trabalho de mulheres profissionais de

enfermagem em um hospital público de Salvador - Bahia. Rev Bras Enferm. 1993;46(3/4):245-57.

6. Lopes MJM. O trabalho da enfermeira: nem público, nem privado, feminino, doméstico e desvalorizado. Rev Bras Enferm. 1988;41(3/4):211-7.

7. Marziale MHP. A postura corporal adotada pela enfermeira durante a execução de seu trabalho. Rev Bras Saúde Ocup. 1991;19(13):19-24.

8. Posso MBS. Fontes potenciais de riscos físicos e químicos: incidentes sobre os membros da equipe cirúrgica [tese]. São Paulo: Universidade de São Paulo; 1988.

9. Rutenfranz J. Trabalhos em turno. São Paulo: Hicitec; 1989.

10. Costa ES, Morita I, Martinez MAR. Percepção dos efeitos do trabalho em turnos sobre a saúde e a vida social em funcionários da enfermagem em um hospital universitário do estado de São Paulo. Cad Saúde Pública. 2000;16(2):553-5.

11. Martino MMF. Estudo comparativo de padrões de sono em trabalhadores de enfermagem dos turnos diurno e noturno. Rev Panam Salud Pública. 2002;12(2):95-100.

12. Júnior $A C S$, Siqueira FPC, Gonçalves BGOG. O trabalho noturno e a qualidade de vida dos profissionais de enfermagem. Reme Rev Min Enferm. 2006;10(1):41-5.

13. Moreno CRC, Fischer FM, Rotenberg L. A saúde do trabalhador na sociedade 24 horas. São Paulo Perspect. 2003;17(1):34-46.

14. Eguia $A E$, Balderas $C$, Gonzáles $L M$. Turno de noche y salud: análisis para determinar los posibeles factores de riesco associados al bajo desempeño físico. Rev Latinoam Salud trab. 2001;1 (1):37-44.

15. Lamond $N$. The impacto $f$ a week of simulated night work on sleep,

circadian phase and performance. Occup Environl Med. 2003;60-6.

16. Harrington JM. Health effects of shift work and extended hours of work.

Occup Environ Med. 2001;58:68-72.

17. Suarez IN. El trabajo a turnos. BIP Publ Inst Ibermutuamur. 1999.

18. Bardin L. Análise de conteúdo. Lisboa: Ediçōes 70; 1977.

19. Barboza DB, Soler ZASG. Afastamento do trabalho na enfermagem: ocorrências com trabalhadores de um hospital de ensino. Rev Latinoam Enferm. 2003;11(2):177-83.

20. Silveira MCJR, Correia EAG. Trabalhadores noturnos na enfermagem e a necessidade de sono. Rev Enferm Atual. 2002;2(10):35-9. 